\title{
Serial ventricular volume measurements: further insights into the aetiology and pathogenesis of benign intracranial hypertension
} \author{
A N D E VEL Y N M T AS D A LE \\ From the Departments of Neurology, Neurosurgery, Physics and Radiology, \\ the Institute of Neurological Sciences, Southern General Hospital, Glasgow
}

ALISON C REID, G M TEASDALE, MARGARETS MATHESON,

SUMMARY Ventricular volumes have been measured from CT scans of patients with benign intracranial hypertension both at initial presentation and at a later date. Volumes initially were smaller than normal, but at review five patients showed a significant increase in ventricular size. Persisting small ventricular volume correlated with persisting symptoms and signs and with persisting obesity. This supports the view that patients with benign intracranial hypertension have brain swelling and that obesity may be implicated in the pathogenesis, perhaps via a neuroendocrine disturbance. It is suggested that weight reduction may be an important component of treatment.

The cause of the raised intracranial pressure in benign intracranial hypertension is controversial; brain swelling or decreased absorption of cerebrospinal fluid have been proposed as the mechanism. Foley ${ }^{1}$ pointed out that, depending on which of these two factors was responsible, the effects on the ventricles would differ (fig 1). In a previous paper we reported that patients with benign intracranial hypertension could be shown, by measurement based on computed tomography, to have small ventricles at the time of their initial presentation. ${ }^{2}$

The safety of CT scanning and, from the patients' point of view, its simplicity make it possible to follow the natural history of the disease in a way that was not permissible with angiography or pneumoencephalography. If the condition were one of brain swelling, the volume of a patient's ventricles would be expected to change in the course of the illness; in particular, resolution of clinical features would be associated with an increase in ventricular volume. We tested this

Address for reprint requests: Dr AC Reid, Department of Neurology, Southern General Hospital,1345 Govan Road, Glasgow G51 4TF, Scotland.

Accepted 18 May 1981 hypothesis by re-examining patients with benign intracranial hypertension at an interval after the initial presentation. We report the changes in ventricular volume and their relationship to the clinical course and to other clinical features, particularly body weight.

\section{Patients and methods}

\section{Patients}

Fifteen female patients with benign intracranial hypertension were reviewed clinically and on the same day re-examined by CT scan. In each patient a diagnosis of benign intracranial hypertension had been made at the time of initial presentation to the Institute of Neurological Sciences, after demonstration of increased CSF pressure and exclusion of a space occupying lesion by the CT scan. The interval between scans ranged from 5 months to 59 months with a mean of 26 months. The ages of the patients at review varied from 12 years to 48 years with a mean of 31 years. Eight patients were significantly overweight. Ideal weight for height was calculated from the Table of Desirable Weights compiled by the Metropolitan Life Insurance Company of America. The American table was used because there are no official data for British women. At the time of the second scan five patients were taking diuretics, three analgesics alone, two steroids and analgesics, and the remaining five 


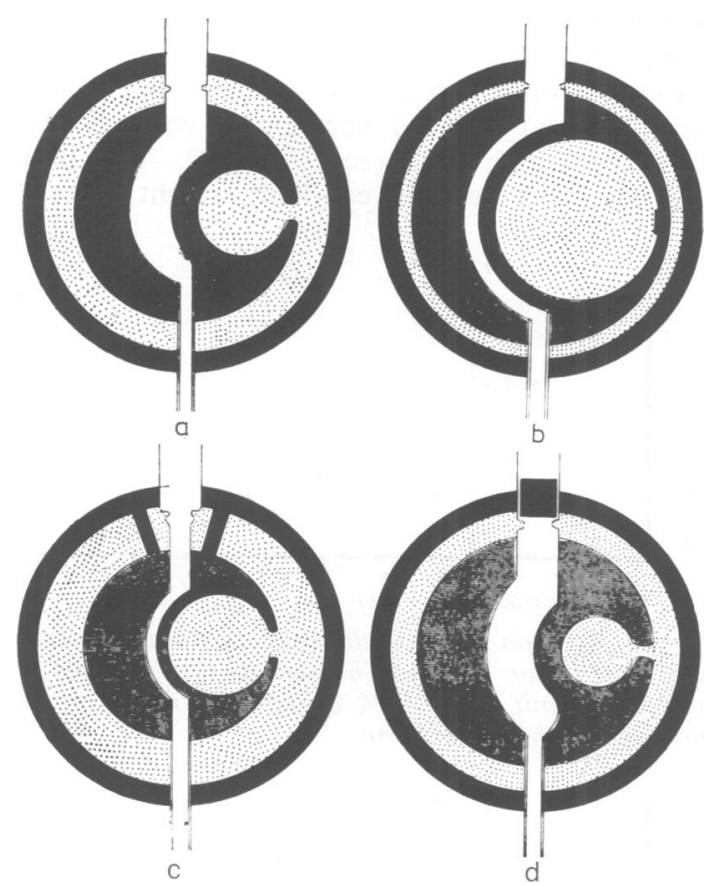

Fig 1 Diagram from Foley 1955 (ref 1) showing (a) representation of the three components of the intracranial system, the incompressible brain tissue (shaded), the vascular system open to the atmosphere, and the CSF (dotted); (b) during ventricular obstruction; (c) when there is obstruction at or near the points of outlet of the CSF; (d) when there is obstruction of the venous outlet.

patients were not receiving any medications (table). The patients were scored with respect to the severity of their symptoms (no headaches $=0$, occasional headaches $=1$, frequent headaches $=2$ ) and fundal appear- ances (no papilloedema $=0$, mild papilloedema $=1$, marked papilloedema $=2$ ). The minimal possible score was thus 0 , while the maximum score of 4 indicated marked persisting symptoms and signs.

\section{Controls}

The 18 female control subjects were similarly agematched with the patients. They had undergone CT scanning as part of the investigation of a variety of neurological complaints. None showed abnormal clinical signs, and in particular no papilloedema. The CT scan was considered to be normal in each case and follow-up examinations have not shown evidence of any developing intracranial pathology.

\section{Measurement of the ventricular volume}

The CT scan data on floppy disc were fed into a Digital PDP-11 computer with a television display. The software "region of interest" facility was used to outline the ventricular region and representative regions of brain tissue. There was no difference in the Hounsfield numbers of the brain in patients and control subjects and we therefore considered pixels with Hounsfield number of less than 20 to represent mainly CSF. The volume of the lateral and third ventricles was calculated by counting the number of pixels deemed to be mainly CSF in each slice and summing the results over the six or eight contiguous slices which comprised the complete scan. The fourth ventricle was not included because it could not be outlined in every case.

\section{Results}

The volume of the ventricles

Ventricular volume of the 18 control subjects ranged from $4.5 \mathrm{ml}$ to $22.0 \mathrm{ml}$ (mean $11.7 \mathrm{ml}$ ). Ventricular volumes of the 15 patients with benign intracranial hypertension at initial presentation ranged from $1.3 \mathrm{ml}$ to $8.4 \mathrm{ml}$ (mean $4.2 \mathrm{ml}$ ) and at follow-up from $1.9 \mathrm{ml}$ to $19.5 \mathrm{ml}$ (mean $6.2 \mathrm{ml}$ )

Table

\begin{tabular}{|c|c|c|c|c|c|c|}
\hline Patients & $\begin{array}{l}\text { Initial } \\
\text { ventricular } \\
\text { volume }(\mathrm{ml})\end{array}$ & $\begin{array}{l}\text { Final } \\
\text { ventricular } \\
\text { volume }(\mathrm{ml})\end{array}$ & $\begin{array}{l}\text { Length of } \\
\text { follow-up } \\
\text { (months) }\end{array}$ & $\begin{array}{l}\text { Clinical } \\
\text { rating scale }\end{array}$ & $\begin{array}{l}\% \text { Deviation } \\
\text { from ideal } \\
\text { weight }\end{array}$ & $\begin{array}{l}\text { Treatment } \\
\text { at review }\end{array}$ \\
\hline $\begin{array}{r}1 \\
2 \\
3 \\
4 \\
5 \\
6 \\
7 \\
8 \\
9 \\
10 \\
11 \\
12 \\
13 \\
14 \\
15\end{array}$ & $\begin{array}{l}3 \cdot 5 \\
5 \cdot 7 \\
3 \cdot 5 \\
1 \cdot 3 \\
5 \cdot 6 \\
8 \cdot 4 \\
1 \cdot 7 \\
4 \cdot 2 \\
4 \cdot 1 \\
1 \cdot 8 \\
4 \cdot 9 \\
4 \cdot 7 \\
3 \cdot 1 \\
4 \cdot 1 \\
3 \cdot 8\end{array}$ & $\begin{array}{r}19.5 \\
12.7 \\
6 \cdot 2 \\
1.9 \\
8.0 \\
11.6 \\
2.3 \\
4.5 \\
4.4 \\
1.9 \\
4.7 \\
4.5 \\
2.9 \\
3.8 \\
3.2\end{array}$ & $\begin{array}{r}54 \\
7 \\
17 \\
17 \\
5 \\
14 \\
13 \\
9 \\
26 \\
29 \\
26 \\
51 \\
32 \\
23 \\
59\end{array}$ & $\begin{array}{l}0 \\
0 \\
0 \\
1 \\
2 \\
1 \\
3 \\
2 \\
3 \\
3 \\
3 \\
4 \\
2 \\
2 \\
2\end{array}$ & $\begin{array}{r}7.5 \\
8.4 \\
0.0 \\
0.0 \\
0.0 \\
-7.0 \\
49.3 \\
0.0 \\
78 \cdot 5 \\
21.3 \\
65.2 \\
23.1 \\
31 \cdot 2 \\
28.9 \\
48.3\end{array}$ & $\begin{array}{l}\text { Frusemide } \\
\text { Nil } \\
\text { Nil } \\
\text { Nil } \\
\text { Acetazolamide } \\
\text { Nil } \\
\text { Acetazolamide + amiloride } \\
\text { Acetazolamide } \\
\text { Prednisolone + analgesics } \\
\text { Acetazolamide } \\
\text { Analgesics } \\
\text { Prednisolone + analgesics } \\
\text { Analgesics } \\
\text { Nil } \\
\text { Analgesics }\end{array}$ \\
\hline
\end{tabular}


(fig 2). The accuracy of the method has been estimated to be $\pm 20 \%$ for volumes over $5 \mathrm{ml}$ and $\pm 1 \mathrm{ml}$ for volumes under $5 \mathrm{ml}^{3}$ an increase in ventricular volume greater than this had occurred in five patients. There was no correlation between initial ventricular volume and the percentage change which had taken place.

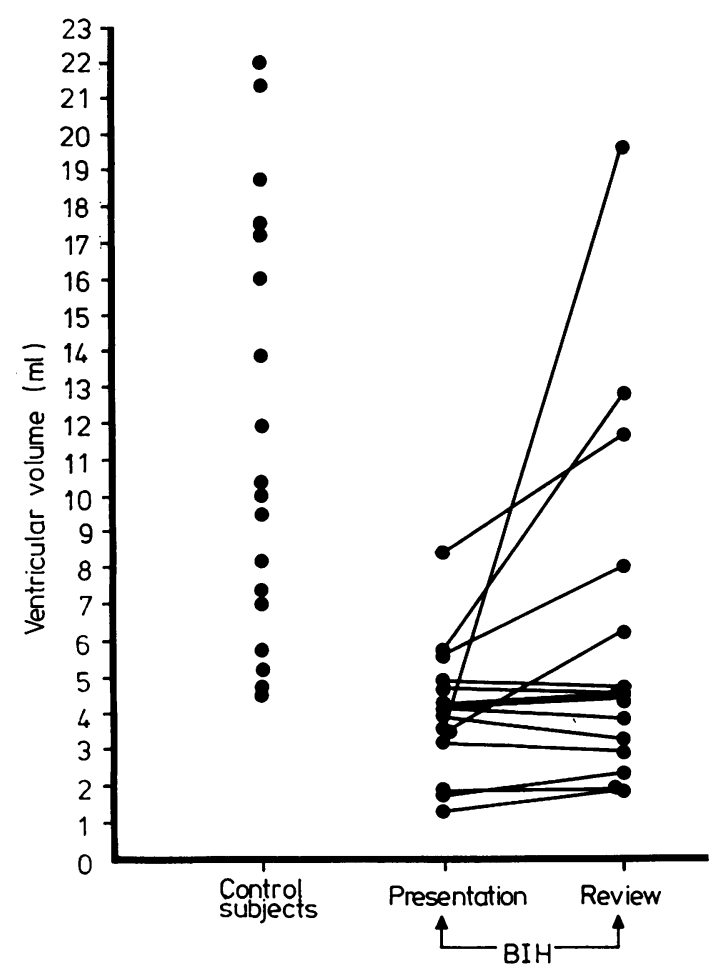

Fig 2 Ventricular volumes of control subjects and patients with benign intracranial hypertension at initial presentation and at review.

\section{Clinical features}

Although we were unable in retrospect to allocate a reliable score to the patients' state at the time of initial presentation, all had marked headaches and papilloedema. At review (table) however, their states ranged from three patients who had no symptoms or papilloedema to one patient with a maximum score of four, who had severe headaches, papilloedema and reduced visual acuity, and was taking corticosteroids. At the time of review several of the patients were markedly overweight (table). Their weight had not been consistently recorded at the time of diagnosis but most patients reported that they had not changed to a marked degree.

\section{Relation between ventricular volume and} clinical features

Patients with low rating scores, that is clinically well, had larger final ventricular volumes than those with high rating scores (fig 3). A relationship was also seen between body weight and clin-

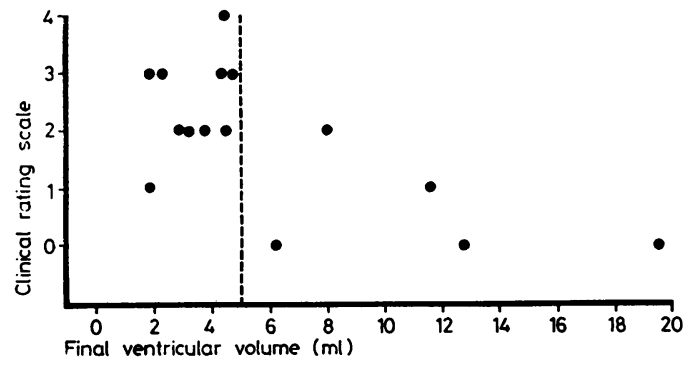

Fig 3 Relation between clinical rating scale at review and ventricular volume. The vertical line represents the lower limit of the $95 \%$ confidence interval for normal ventricular volume.

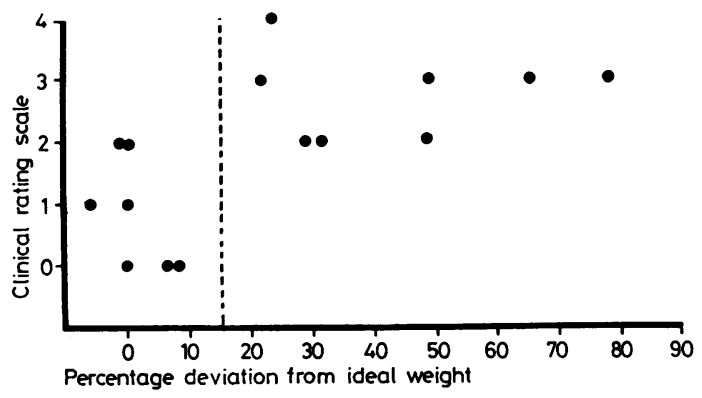

Fig 4 Relation between clinical rating scale and deviation from ideal weight. The vertical line represents $15 \%$ above ideal weight.

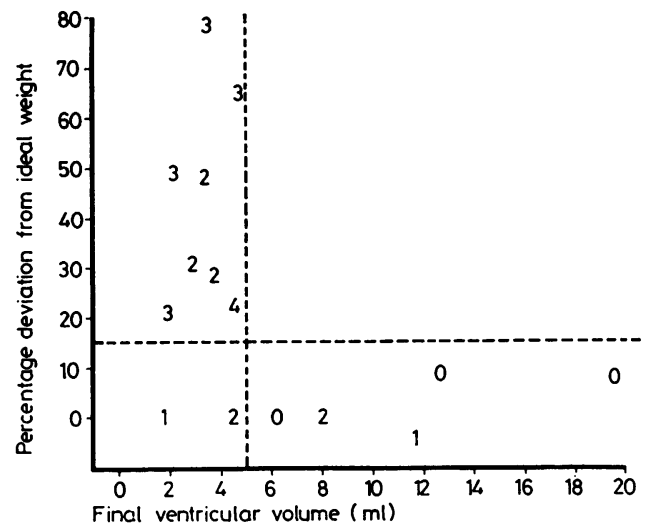

Fig 5 Relation between clinical state, body weight and final ventricular volume. 
ical progress. Patients of normal weight had low scores and were clinically well, whereas those who were more than $15 \%$ overweight had higher rating scores (fig 4). Figure 5 shows the relation between ventricular volume, weight and clinical score. It can be seen that patients with larger final ventricular volumes had normal weights and no or mild symptoms, whereas those with persisting small ventricles tended to be more than $15 \%$ overweight and still to have symptoms and signs.

\section{Discussion}

This is the first study in which ventricular volumes of patients with benign intracranial hypertension have been studied serially. Previous studies with CT scan have concentrated on its use as a diagnostic tool that may allow the exclusion of a space occupying lesion with a high degree of accuracy without the use of invasive techniques. ${ }^{4}$ The small ventricular volumes which we previously showed to be present at initial presentation were found to increase in some patients and to remain unchanged in others. Patients whose ventricles had returned to a size within the normal range were clinically better at review than those whose ventricles were persistingly small.

That patients with benign intracranial hypertension have small ventricles at the time of initial presentation and that a subsequent increase in ventricular volume into the normal range is associated with clinical improvement, is further evidence in favour of the condition being due to brain swelling. If the primary pathogenic mechanism were decreased absorption of CSF, ${ }^{5}$ then one would expect to see initially large ventricles which become smaller with clinical improvement. One of the objections which has often been raised to attributing the cause of the raised intracranial pressure in patients with benign intracranial hypertension to oedema or brain swelling is their remarkably well preserved conscious state. However, in the presence of extracellular or vasogenic oedema, normal neurological function and electrical function are preserved ${ }^{6} 7$ and it is only when secondary factors such as tissue tension gradients, brain shifts and reduced cerebral blood flow come into operation that neurological function is impaired. Another factor which some regard as evidence against benign intracranial hypertension being a form of brain swelling is the undoubted efficacy of ventricular shunts and lumbar punctures. On the other hand, ventricular shunting may have a non-specific effect in relieving intracranial hypertension by the venting of CSF, whether or not this is the intracranial compartment which is primarily expanded. Similarly, the benefit of lumbar punctures may be by a nonspecific mechanism. Because the brain swelling is generalised, lumbar punctures will result in an even reduction in pressure and will not produce pressure gradients; thus there is not the same danger of subsequent shift or coning as there would be if a mass lesion were present.

The Hounsfield numbers of the brains of patients and controls are similar but this does not exclude the presence of brain swelling, nor of it being due to either increased cerebral blood volume or increased brain water. The protein content of oedema fluid can mask any decrease in Hounsfield number brought about by increased brain water. $^{8}$

An obstruction of venous outflow would be likely to produce small ventricles ${ }^{1}$ and could lead to increased brain water and decreased absorption of CSF. Prior to introduction of the CT scan, however, many patients had carotid angiograms, and evidence of sinus thrombosis was lacking. Although some cases of so-called "otitic hydrocephalus" were attributed to venous sinus thrombosis, there is no evidence of venous obstruction in these patients with idiopathic benign intracranial hypertension.

Obesity may be an important aetiological factor in benign intracranial hypertension: certainly patients with persisting symptoms were strikingly obese compared with those whose symptoms had resolved. In the past little attention has been paid to obesity as a prognostic feature, but Weisberg ${ }^{9}$ surveyed 120 patients with benign intracranial hypertension and noted that of those whose symptoms resolved within three months only $33 \%$ were obese. By contrast, $90 \%$ of patients whose symptoms persisted for at least 12 months were obese. The persisting small ventricles demonstrated in several patients with chronic papilloedema and continuing headaches emphasises the fact that there should be no complacency in the management of these patients. They may need close supervision for long periods and weight reduction may be an important component of their management.

The blood-brain barrier is not freely permeable to water ${ }^{10}$ and certain neuroendocrine influences have been demonstrated to be important in regulation of its permeability. ${ }^{11}{ }^{12}$ Obesity is recognised to be associated with adaptive endocrine changes in response to the imbalance between caloric intake and energy output ${ }^{13}$ and we suggest that obese persons with idiopathic intracranial hyper- 
tension may have neuroendocrine disturbances that lead to increased brain water content.

\section{References}

1 Foley J. Benign forms of intracranial hypertension-"toxic" and "otitic" hydrocephalus. Brain 1955; 78:1-41.

2 Reid AC, Matheson MS, Teasdale G. Volume of the ventricles in benign intracranial hypertension. Lancet 1980; ii:7-8.

3 Wyper DJ, Pickard JD, Matheson M. Accuracy of ventricular volume estimation. J Neurol Neurosurg Psychiatry 1978; 42:345-50.

4 Weisberg L, Nice CN. Computed tomographic evaluation of increased intracranial pressure without localising signs. Radiology 1977; 122:133-6.

5 Johnston I. Reduced CSF absorption syndrome. Reappraisal of benign intracranial hypertension and related syndromes. Lancet 1973; 2:418-21.

6 Penn RD. Cerebral oedema and neurological function in human beings. Neurosurgery 1980; 6:249-52.

7 Sutton LN, Bruce DA, Welsh FA, Jaggi JL. Metabolic and electrophysiologic consequences of vasogenic oedema. In: Cervós-Navarro J,
Ferszt R, eds. Advances in Neurology. New York: Raven Press 1980; 28:241-54.

8 Penn RD. Cerebral oedema and neurological function: CT, evoked responses and clinical examination. In: Cervós-Navarro J, Ferszt $R$, eds. Advances in Neurology. New York: Raven Press 1980; 28:383-94.

9 Weisberg LA. Benign intracranial hypertension. Medicine 1975; 54:197-207.

10 Raichle ME, Eichling JO, Straatmann MG, Welch MJ, Larson KB, Ter-Pogossian MM. Blood-brain barrier permeability of ${ }^{11} \mathrm{C}$-labelled alcohols and ${ }^{15} \mathrm{O}$-labelled water. Am J Physiol 1976; 230:543-52.

11 Raichle ME, Hartman BK, Eichling JO, Sharpe LG. Central noradrenergic regulation of cerebral blood flow and vascular permeability. Proc Natl Acad Sci USA 1975; 72:3726-30.

12 Raichle ME, Grubb RL, Eichling JO. Central neuroendocrine regulation of brain water permeability. In: Cerebral Vascular Smooth Muscle and its Control Ciba Found Sympos Elsevier 1978; 56:219-26.

13 Hall R, Anderson J, Smart GA, Besser M. Fundamentals of Clinical Endocrinology. Pitman Medical 1974; 2nd ed. 372. 